\title{
Article \\ GhKWL1 Upregulates GhERF105 but Its Function Is Impaired by Binding with VdISC1, a Pathogenic Effector of Verticillium dahliae
}

\author{
Yang Chen, Mi Zhang, Lei Wang, Xiaohan Yu, Xianbi Li, Dan Jin, Jianyan Zeng, Hui Ren, Fanlong Wang, \\ Shuiqing Song, Xingying Yan, Juan Zhao and Yan Pei *
}

check for updates

Citation: Chen, Y.; Zhang, M.; Wang, L.; Yu, X.; Li, X.; Jin, D.; Zeng, J.; Ren, H.; Wang, F.; Song, S.; et al. GhKWL1 Upregulates GhERF105 but Its Function Is Impaired by Binding with VdISC1, a Pathogenic Effector of Verticillium dahliae. Int. J. Mol. Sci. 2021, 22, 7328. https://doi.org/10.3390/ijms22147328

Academic Editor: Zhixiang Chen

Received: 1 June 2021

Accepted: 2 July 2021

Published: 8 July 2021

Publisher's Note: MDPI stays neutral with regard to jurisdictional claims in published maps and institutional affiliations.

Copyright: (c) 2021 by the authors. Licensee MDPI, Basel, Switzerland. This article is an open access article distributed under the terms and conditions of the Creative Commons Attribution (CC BY) license (https:/ / creativecommons.org/licenses/by/ $4.0 /)$.
Biotechnology Research Center, Southwest University, No. 2 Tiansheng Road, Beibei, Chongqing 400716, China; mtchy2008@email.swu.edu.cn (Y.C.); selenazm@swu.edu.cn (M.Z.); w1407002131@email.swu.edu.cn (L.W.); yuwen970526@email.swu.edu.cn (X.Y.); lxianbi@swu.edu.cn (X.L.); jindancj@swu.edu.cn (D.J.); zengjianyan@swu.edu.cn (J.Z.); renhui@email.swu.edu.cn (H.R.); wfl2015@email.swu.edu.cn (F.W.); shuiqingsong@126.com (S.S.); yxingying@swu.edu.cn (X.Y.); zhaojuan0920@swu.edu.cn (J.Z.)

* Correspondence: peiyan3@swu.edu.cn; Tel.: +86-23-68-25-1883; Fax: +86-23-68-25-0515

\begin{abstract}
Verticillium wilt, caused by Verticillium dahliae, is a devastating disease for many important crops, including cotton. Kiwellins (KWLs), a group of cysteine-rich proteins synthesized in many plants, have been shown to be involved in response to various phytopathogens. To evaluate genes for their function in resistance to Verticillium wilt, we investigated KWL homologs in cotton. Thirtyfive KWL genes (GhKWLs) were identified from the genome of upland cotton (Gossypium hirsutum). Among them, GhKWL1 was shown to be localized in nucleus and cytosol, and its gene expression is induced by the infection of $V$. dahliae. We revealed that GhKWL1 was a positive regulator of GhERF105. Silencing of GhKWL1 resulted in a decrease, whereas overexpression led to an increase in resistance of transgenic plants to Verticillium wilt. Interestingly, through binding to GhKWL1, the pathogenic effector protein VdISC1 produced by $V$. dahliae could impair the defense response mediated by GhKWL1. Therefore, our study suggests there is a GhKWL1-mediated defense response in cotton, which can be hijacked by $V$. dahliae through the interaction of VdISC1 with GhKWL1.
\end{abstract}

Keywords: kiwellins; Verticillium dahliae; GhERF105; VdISC1; cotton

\section{Introduction}

Cotton, the leading fiber crop of the world, is widely planted in more than 80 countries [1]. However, cotton production is limited by biotic stresses, of which the most serious one is Verticillium wilt caused by members of the fungal genus Verticillium [2-4]. Verticillium has a broad host range of more than 300 woody and herbaceous plant species. Verticillium dahliae and $V$. alboatrum, among the most notorious species, cause billion-dollar losses annually worldwide. The soil habitat and their long-term survival for years make control of the pathogen difficult, and thus, Verticillium wilt is the focus of extensive research and management attention $[2,5]$.

During infection, Verticillium spp. produce a battery of proteins, including walldegrading enzymes, transcription factors, and membrane receptors, to facilitate host colonization, often by disturbing host immunity [6]. Putatively, $V$. dahliae secretes more than 700 proteins, also known as effectors [7], which either emphasize pathogenic virulence by overcoming plant defense responses or are directly/indirectly recognized by host surveillance systems, leading to effector-triggered immunity [8]. Some of these effectors interfere with host hormone signaling, by which the pathogens can use the host resources to their advantage $[9,10]$. For example, in the process of colonization, $V$. dahliae produces VdISC1, an unconventionally secreted isochorismate mutase that converts isochorismate into 2,3-dihydro-2,3-dihydroxybenzoate (DDHB), to inhibit the biosynthesis 
of salicylic acid (SA) by greatly reducing the accumulation of the SA precursor isochorismate [11] and thereby downregulates the plant innate immune response against biotrophic pathogens [12].

Sustained efforts have been made to identify effective approaches to modify plant resistance to Verticillium wilt. For example, in cotton, the overexpression of various proteins and small RNAs, such as thioredoxin GbNRX1, major latex protein GhMLP28, laccase GhLAC1, lysin-motif receptor kinases (GhLYK1 and GhLYK2), microRNAs (miR166 and miR159), and transcription factors (GhbHLH171, GbWRKY1, GhMYB108, and GbERF1), is reported to be able to enhance plant resistance to Verticillium wilt [13-22]. Among these proteins, ethylene response factors (ERFs), belonging to the superfamily of APETALA2 (AP2)/ERF transcription factors, have been implicated in regulating the plant defense response [15,23-28]. Plants with changed expression of ERF genes display altered disease susceptibility, which is associated with transcriptional regulation of defense-related genes, such as PDF1.2 and pathogenesis-related (PR) genes [29-34]. Increasing evidence has revealed that $E R F$ genes are involved in resistance to Verticillium wilt in cotton $[15,17,35-37]$. The expression levels of PDF1.2 and PR5 genes are remarkably reduced in GhERF6-silenced cotton plants [15]. The overexpression of GbERF1-like improves Verticillium wilt resistance in both cotton and Arabidopsis, and the expression of PR3 and PR4 genes is upregulated in GbERF1-like-overexpressing cotton plants [35].

Kiwellins (KWLs), a group of cysteine-rich proteins that are among the major protein components of kiwifruit (Actinidia chinensis) [38-40], were initially identified as a novel substance that causes food allergic reactions [38,41-43]. The expression of KWL genes is highly upregulated during the plant response to pathogenic infection and whitefly infestation [7,44-47]. Recent research has revealed that two paralogs in maize (Zea mays), ZmKWL1 and ZmKWL1-b, function redundantly in smut disease resistance [48,49]. ZmKWL1 disables the effector UmCmu1, which can prevent the biosynthesis of salicylic acid through physical interaction and, in turn, secures the plant defense response [48]. Similarly, ZmKWL1-b, the closest homolog to ZmKWL1, is able to interact with UnCmu1 and considerably reduce the pathogenicity to the plant [49]. However, given their obscure functions and absence in the Brassicaceae [48], including the model plant Arabidopsis, the roles of KWL family members are poorly understood.

In this study, we identified multiple GhKWL genes in the upland cotton genome. Among the pathogen-inducible GhKWLs, GhKWL1 was localized in the nucleus and positively regulated plant resistance to $V$. dahliae infection through an ERF-mediated pathway. In turn, VdISC1, an effector of $V$. dahliae, could interact with GhKWL1 to attenuate the GhKWL1-GhERFs-mediated plant defense response. Overexpression of GhKWL1 significantly increased cotton resistance to Verticillium wilt.

\section{Results}

\subsection{GhKWL1 Is Induced by V. dahliae and the Protein Is Located in the Nucleus}

We used KWL protein sequences of Z. mays and A. chinensis to query the reference genome of G. hirsutum [50]. A total of 35 homologous genes were identified, of which 13 genes originated from the A subgenome and 22 genes from the D subgenome (Supplementary Materials, Figure S1). These GhKWLs were expressed globally in the roots, stems, and leaves with various transcription levels (Supplementary Materials, Figure S2A). After a challenge with $V$. dahliae strain V991, four GhKWL genes (GhKWL1, GhKWL2, GhKWL3, and GhKWL4) were remarkably upregulated (Supplementary Materials, Figure S2B), suggesting that these four genes may be involved in the response of cotton to $V$. dahliae infection. A multiple sequence alignment of ZmKWL1, AcKWL1 [38,42,48], and GhKWL1 to GhKWL4 revealed that the protein sequences were relatively conserved in the central and C-terminal regions but divergent in the N-terminal tails (Supplementary Materials, Figure S3). The prediction of subcellular localization suggested that GhKWL1 might be a nuclear or cytoplasmic protein, GhKWL4 a nuclear or apoplastic protein, and GhKWL2 and 3 might be apoplastic proteins (Supplementary Materials, Table S1). To verify the localization, the four 
GhKWL genes were fused with the green fluorescent protein gene (GFP) at the C-terminal, and the GFP-tagged genes were transformed into leaves of tobacco (Nicotiana benthamiana) using Agrobacterium-mediated infiltration. The fusion protein GhKWL1:GFP was mainly localized in the nucleus and at the periphery of pavement cells (Figure 1A), whereas the other three fusion proteins, including GhKWL4:GFP, were localized at the cell periphery, and no nuclear localization was observed (Supplementary Materials, Figure S4). Plasmolysis further indicated that GhKWL1:YFP was not located in the apoplast (Figure 1B).

A

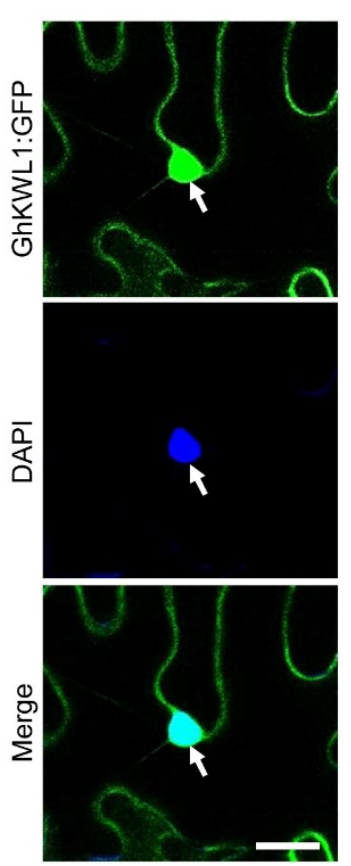

B

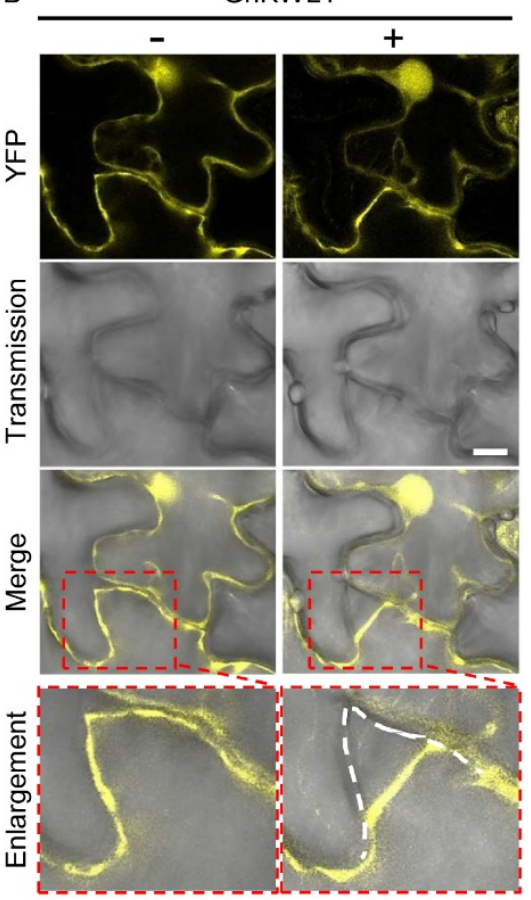

Figure 1. The subcellular localization of GhKWL1. (A) Colocalization of the GhKWL1:GFP fusion protein with DAPI-stained nucleus in tobacco (Nicotiana benthamiana) pavement cells. Agrobacterium tumefaciens infiltration solution containing the pro35S:GhKWL1:GFP vector was infiltrated into tobacco leaves. After $3 \mathrm{~d}$, the infiltrated leaves were stained with DAPI for $20 \mathrm{~min}$, and the fluorescence signals were observed. The white arrows indicate the nucleus. DAPI, a fluorescent dye of DNA. Merge, overlay of green and blue fluorescence images. (B) Subcellular localization of GhKWL1:YFP after plasmolysis. Agrobacterium tumefaciens infiltration solution containing the pro35S:GhKWL1:YFP vector was infiltrated into tobacco leaves. After $3 \mathrm{~d}$, the infiltrated leaves were imaged $(-)$ and then treated with $30 \%(w / v)$ sucrose solution $(+)$ for plasmolysis. Merge, overlay of fluorescence and transmission images. Regions enclosed in the red boxes are enlarged in the bottom panel. The white dotted line represents the cell wall. Scale bars represent $50 \mu \mathrm{m}$ (in (A)) and $25 \mu \mathrm{m}$ (in (B)).

\subsection{Downregulation of GhKWL1 Decreases, While Overexpression of GhKWL1 Increases, Resistance to $V$. dahliae Infection}

We then employed virus-induced gene silencing (VIGS) to examine the role of GhKWL1 in the resistance of cotton to Verticillium wilt. Two weeks after infiltration, the transcription level of GhKWL1 was significantly reduced by $~ 90 \%$ compared with that of the control (Figure 2A). The plants were then inoculated with $V$. dahliae strain V991 for $20 \mathrm{~d}$. The knockdown of GhKWL1 resulted in disease symptoms of increased severity, including wilting, chlorosis, and necrosis, as well as xylem browning than those of the parallel control (Figure 2B,C). Statistically, the disease index of TRV:GhKWL1 plants was significantly higher than that of the control (Figure 2D). The estimation of the fungal biomass in the leaves by quantitative PCR indicated that more fungi colonized the GhKWL1-silenced plants than the control (Figure 2E). Downregulation of GhKWL1 suggested that the gene is involved in the resistance of plants to Verticillium wilt. 
A
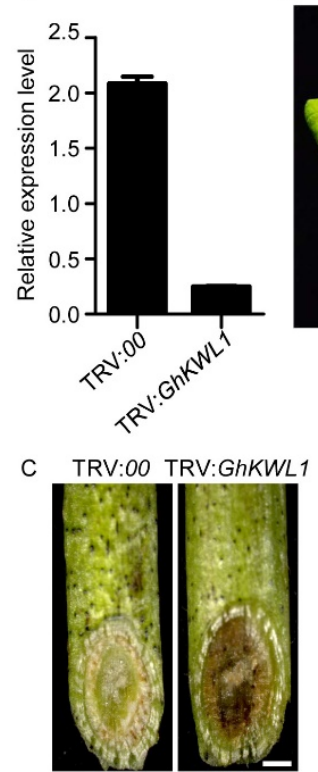

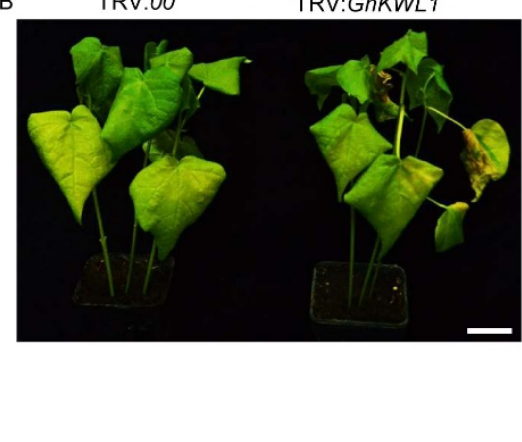

D

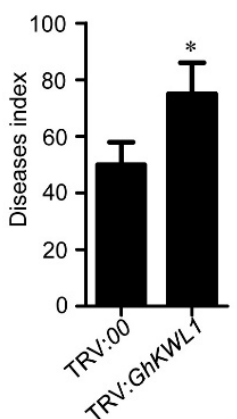

G
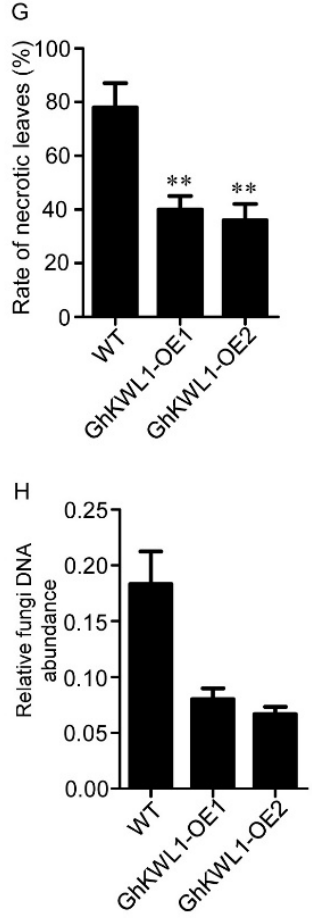

Figure 2. The downregulation of GhKWL1 enhances the susceptibility of cotton to V. dahliae infection, and the overexpression of GhKWL1 enhances the resistance of Arabidopsis to V. dahliae infection. (A) The expression level of GhKWL1 in leaves of GhKWL1-silenced (TRV:GhKWL1) plants and the parallel control (TRV:00). Total RNAs were extracted from leaves of cotton plants after 2 weeks of virus-induced gene silencing of GhKWL1. (B) Disease symptoms of TRV:00 and TRV:GhKWL1 cotton plants infected with $V$. dahliae. Seedlings after 2 weeks of virus-induced gene silencing of GhKWL1 were inoculated with $10 \mathrm{~mL} V$. dahliae conidial suspension $\left(10^{7}\right.$ conidia $\left./ \mathrm{mL}\right)$ for $20 \mathrm{~d}$. The scale bar represents $3 \mathrm{~cm}$. (C) Sections of TRV:00 and TRV:GhKWL1 cotton stems at $20 \mathrm{~d}$ post-inoculation (dpi). The brown areas are diseased vascular bundles. The scale bar represents $1 \mathrm{~mm}$. (D) Disease index of TRV:00 and TRV:GhKWL1 cotton plants at 20 dpi. Three independent replicates were performed, with at least 20 plants being measured per VIGS event and replicate. Asterisks indicate statistical significance as determined by Student's $t$-test $\left({ }^{*} p<0.05\right)$. (E) Fungal DNA abundance in leaves of TRV:00 and TRV:GhKWL1 cotton plants. The DNA was isolated from upland cotton leaves at $20 \mathrm{dpi}$. (F) Disease symptoms of Arabidopsis infected with $V$. dahliae. Three-week-old Arabidopsis plants were inoculated with $V$. dahliae for $25 \mathrm{~d}$. Three independent replicates were performed, with at least 20 plants being measured per transgenic event and replicate. (G) Percentage of necrotic leaves in the Arabidopsis plants at $25 \mathrm{dpi}$. Asterisks indicate statistical significance as determined by Student's $t$-test $\left.{ }^{* *} p<0.01\right)$. (H) Fungal DNA abundance in leaves of the Arabidopsis plants. The DNA was isolated from Arabidopsis leaves at $25 \mathrm{dpi}$. The relative level was determined by quantitative RT-PCR $(\mathbf{A}, \mathbf{E}, \mathbf{H})$. GhUBQ7 served as the reference gene in cotton $(\mathbf{A}, \mathbf{E}) ; A t A C T I N 2$ served as the reference gene in Arabidopsis (H). 
To confirm the role of GhKWL1 in the resistance to Verticillium wilt, we expressed the gene under the control of the Cauliflower mosaic virus $35 \mathrm{~S}$ promoter (35S) in Arabidopsis. Two lines ( $\mathrm{T}_{3}$ generations) derived from independent transformants that showed a high expression level of GhKWL1 were selected for further study (Supplementary Materials, Figure S5). Three-week-old plants were inoculated with a conidial suspension of $V$. dahliae strain V991. After $25 \mathrm{~d}$, wilting, chlorosis, and necrosis symptoms were observed in the wildtype plants (Figure 2F). The 35S:GhKWL1 Arabidopsis transformants exhibited much less severe symptoms: the plants were larger than the wild type, and few leaves turned yellow (Figure 2F). The percentage of necrotic leaves of 35S:GhKWL1 Arabidopsis transformants was significantly lower than that of the wild-type control (Figure 2G). The abundance of fungal DNA in the GhKWL1-overexpressing leaves was significantly lower than that of the control (Figure 2H). These results indicate that heterologous overexpression of GhKWL1 can increase the resistance of Arabidopsis to V. dahliae infection.

\subsection{GhKWL1 Upregulates Transcription of GhERFs}

An autoactivation activity assay showed that the complete GhKWL1 protein possessed strong autoactivation activity (Supplementary Materials, Figure S6). The nuclear localization of GhKWL1 and the autoactivation activity of GhKWL1 imply that this protein may participate in regulating genes involved in the defense response against $V$. dahliae infection. To understand how GhKWL1 confers resistance to $V$. dahliae infection, we used transcriptomics to investigate genes that are downregulated in GhKWL1-silenced plants vs. the control. In total, 561 genes that showed at least six-fold downregulation were detected, including genes involved in the transcriptional factor-related cellular processes, such as DNA binding transcription activity and transcription regulator activity, were detected (Figure 3A). Among these genes, 22 ethylene response factor (GhERF) genes were markedly downregulated in GhKWL1-silenced plants (Figure 3B). Quantitative RT-PCR (qRT-PCR) analysis further showed that four of these genes (GhERF105, GhRAP2, GhERF106, and GhERF003) were largely repressed compared with expression levels in the control plants (Figure 3C). We then selected GhERF105, one of the markedly downregulated genes, to test whether its transcription is directly upregulated by GhKWL1. A dual-luciferase assay showed that, under the expression of GhKWL1, the transcriptional activity of GhERF105 was significantly upregulated (Figure 3D).

\subsection{Suppression of GhERF105 Increases the Susceptibility of Cotton to V. dahliae Infection}

We then tested whether GhERF105 is involved in plant resistance to $V$. dahliae infection. The expression of GhERF105 was significantly suppressed by VIGS (Figure 4A). The resultant knockdown cotton plants were infected with $V$. dahliae strain V991. After $20 \mathrm{~d}$, GhERF105-silenced plants exhibited worse disease symptoms of chlorosis and xylem browning compared with the control (Figure 4B,C). The disease index and fungal abundance confirmed that the TRV:GhERF105 plants were more susceptible to infection (Figure 4D,E). It has been reported previously that the expression of PDF1.2 and PR4 is positively regulated by ERFs in cotton [15,35]. As expected, transcription of these two genes was decreased in GhERF105-silenced or GhKWL1-silenced cotton (Figure 4F,G). Conversely, the expression of AtPDF1.2 and AtPR4 in 35S:GhKWL1 Arabidopsis was noticeably increased (Figure $4 \mathrm{H})$. These results suggested that PDF1.2 and PR4 were upregulated by GhKWL1 and GhERF105. 

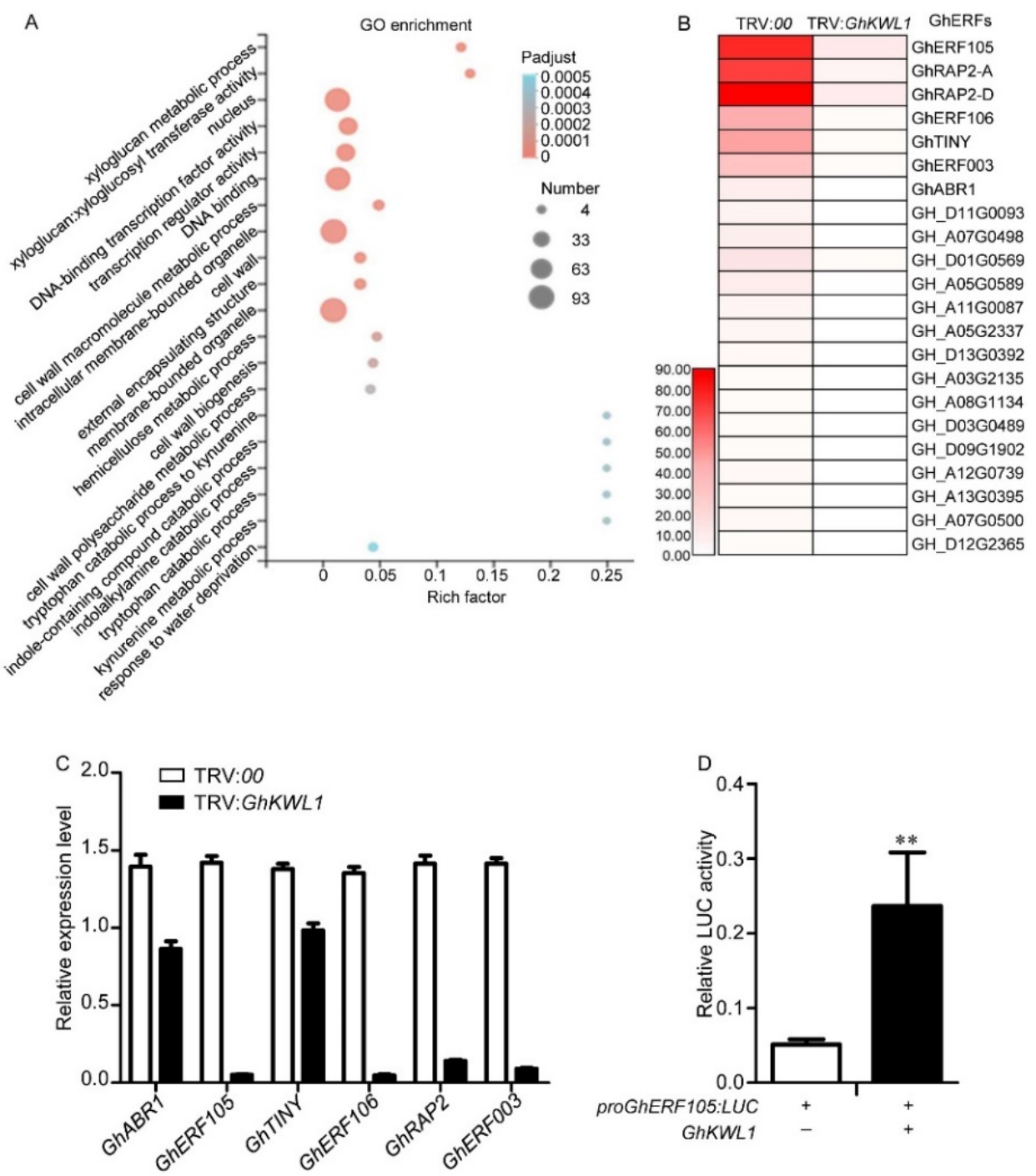

Figure 3. GhKWL1 plays a positive role in upregulating the expression of GhERF genes. (A) Gene ontology (GO) enrichment of downregulated genes in GhKWL1-silenced plants (TRV:GhKWL1) vs. the control (TRV:00). The $x$-axis represents the Rich Factor. The greater the value, the greater the enrichment degree. The $y$-axis represents various GO terms. The bubble size indicates the number of differential genes in each GO term. The color code indicates the $\mathrm{P}$ adjust value. If the $p$ adjust value $<0.05$, the pathway was defined as a significantly enriched GO term. (B) Heat map of the relative expression level of GhERF genes (determined by RNA-seq reads) in GhKWL1-silenced plants and the control (TRV:00). Total RNAs were extracted from leaves of cotton plants after 2 weeks of virus-induced gene silencing of GhKWL1 and used for RNA-seq analysis. (C) Relative expression levels of GhERF genes in GhKWL1silenced (TRV:GhKWL1) plants and the control (TRV:00). Total RNAs were extracted from leaves of cotton plants after 2 weeks of virus-induced gene silencing of GhKWL1. The relative level was determined by quantitative RT-PCR. GhUBQ7 served as the reference gene. GhERF105 represents GH_A03G0725; GhRAP2-A represents GH_A05G1425; GhRAP2-D represents GH_D05G1440; GhERF106 represents GH_D07G0504; GhTINY represents GH_D10G1125; GhERF003 represents GH_D05G0585; GhABR1 represents GH_A02G1617. (D) The promoter of GhERF105 was activated by the expression of GhKWL1. The luciferase activity was determined by the LUC/REN ratio. Asterisks indicate statistical significance as determined by Student's $t$-test $\left.{ }^{* *} p<0.01\right)$. 


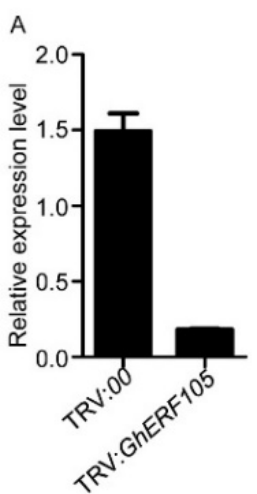

C
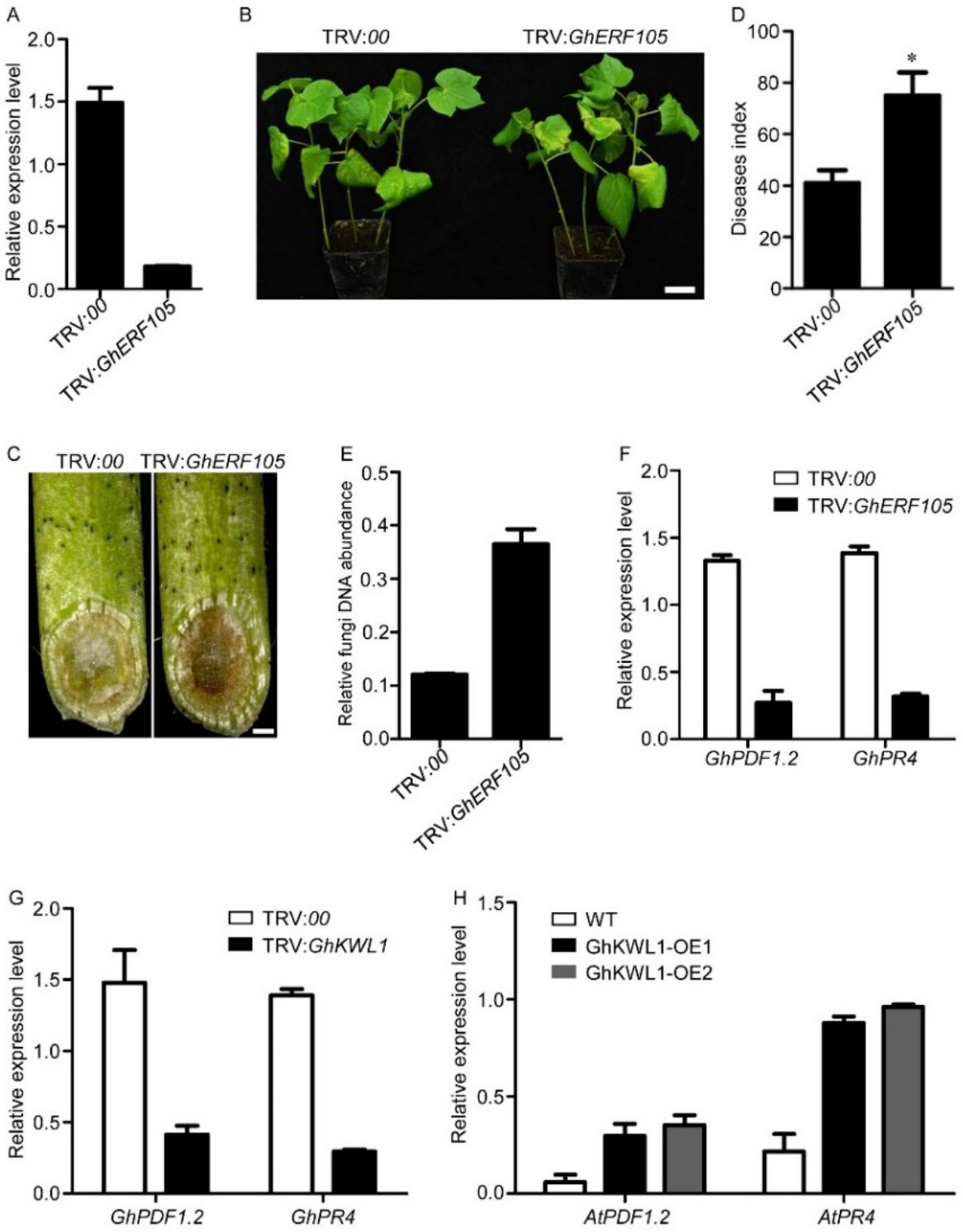

Figure 4. The downregulation of GhERF105 attenuates cotton resistance to $V$. dahliae infection. (A) The expression of GhERF105 in leaves of cotton plants after 2 weeks of virus-induced gene silencing of GhERF105. (B) Disease symptoms of cotton plants at $20 \mathrm{~d}$ post-inoculation. The roots of cotton seedlings after 2 weeks of virus-induced gene silencing of GhERF105 were irrigated with $10 \mathrm{~mL}$ of $V$. dahliae conidial suspension $\left(10^{7}\right.$ conidia $\left./ \mathrm{mL}\right)$. The scale bar represents $3 \mathrm{~cm}$. (C) Sections of TRV:00 and TRV:GhERF105 cotton stems. The brown areas are diseased vascular bundles. The scale bar represents $1 \mathrm{~mm}$. (D) The disease index of TRV:00 and TRV:GhERF105 plants at $20 \mathrm{dpi}$. Three independent replicates were performed, with at least 20 plants being measured per VIGS event and replicate. Asterisks indicate statistical significance as determined by Student's $t$-test $\left(^{*} p<0.05\right)$. (E) Fungal DNA abundance in leaves of TRV:00 and TRV:GhERF105 cotton. The DNA was isolated from cotton leaves at 20 dpi. (F) Expression levels of GhPDF1.2 and GhPR4 in TRV:00 and TRV:GhERF105 cotton plants. Total RNAs were extracted from the cotton leaves after 2 weeks of virus-induced gene silencing of GhERF105. (G) Expression levels of GhPDF1.2 and GhPR4 in TRV:00 and TRV:GhKWL1 cotton plants. Total RNAs were extracted from the cotton leaves after 2 weeks of virus-induced gene silencing of GhKWL1. (H) Expression levels of AtPDF1.2 and AtPR4 in wild-type Arabidopsis and 35S:GhKWL1 transgenic Arabidopsis lines. Total RNAs were extracted from 3-week-old Arabidopsis leaves. The relative level was determined by quantitative RT-PCR $(\mathbf{A}, \mathbf{E}-\mathbf{H})$. GhUBQ7 served as the reference gene in cotton $(\mathbf{A}, \mathbf{E}, \mathbf{F}) ;$ AtACTIN2 served as the reference gene in Arabidopsis (H). 


\subsection{VdISC1 Interacts with GhKWL1 and Inhibits Transcription of GhKWL1}

It was previously reported that ZmKWL1 interacts with UmCmu1, a fungal effector of Ustilago maydis, and deactivates the protein to ensure the SA-mediated plant defense response to infection by the pathogen [48]. VdISC1 is an isochorismatase secreted by $V$. dahliae and functions in the same pathway as UmCmu1 to inhibit the conversion of the molecule isochorismate to SA in plants [11]. A bimolecular fluorescence complementation $(\mathrm{BiFC})$ assay showed that both VdISC1 and its loss of catalytic activity mutant VdISC1 ${ }^{3 \mathrm{~A}}$ were able to interact with GhKWL1 in the nucleus and endomembrane (Figure 5A). This interaction was further confirmed by a co-immunoprecipitation (Co-IP) assay (Figure 5B,C). In the presence of either VdISC1 or VdISC1 ${ }^{3 \mathrm{~A}}$, the activity of the GhERF105 promoter caused by GhKWL1 was strikingly decreased (Figure 5D). These data suggest that VdISC1 is a negative regulator for the GhKWL1-GhERF105 pathway.

A

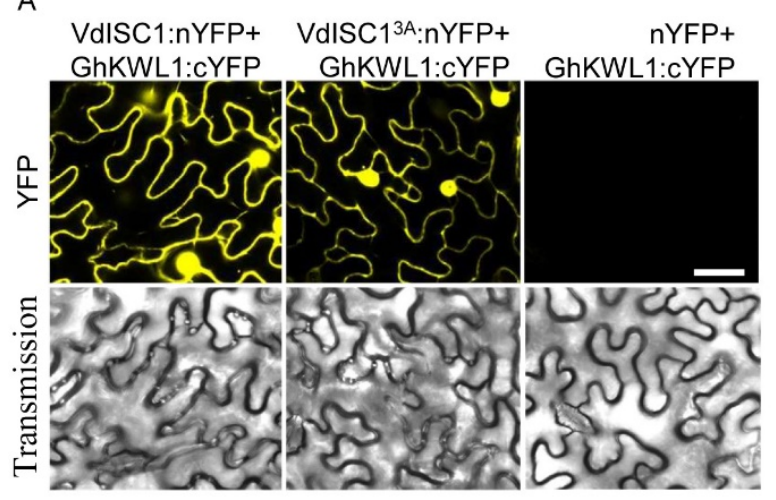

C

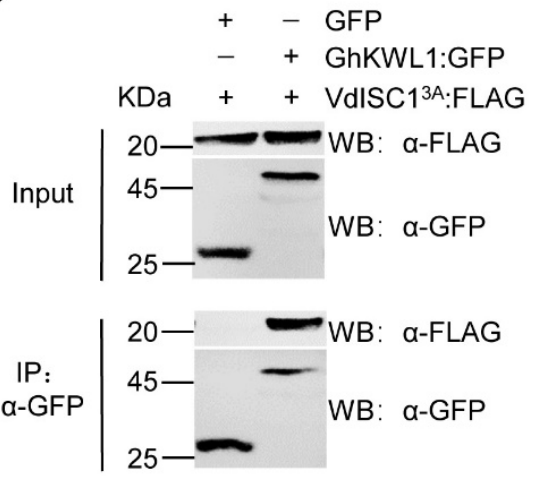

B
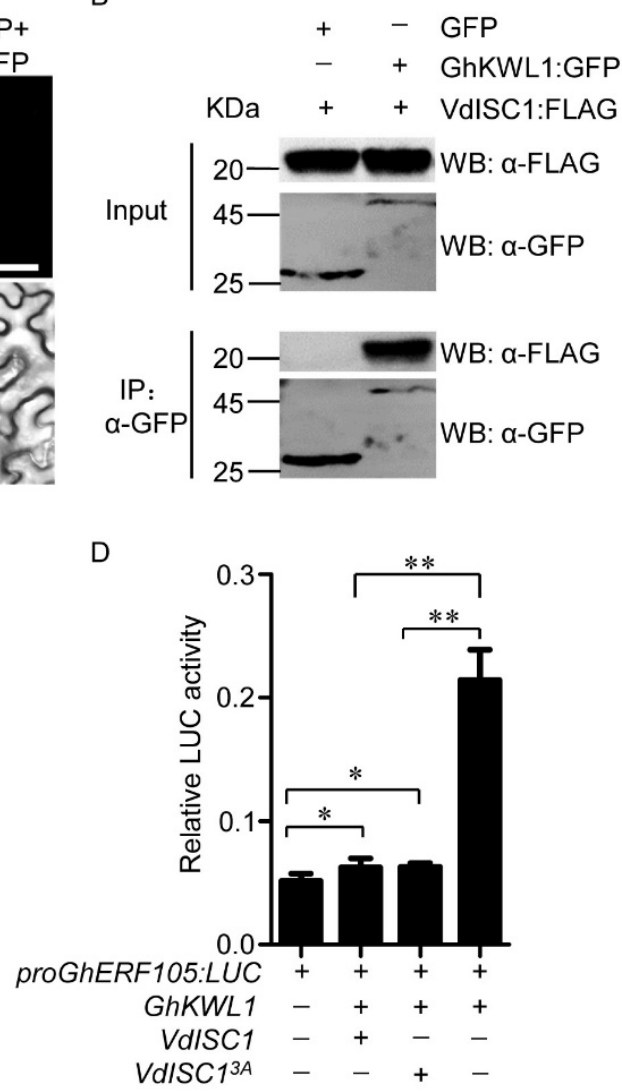

Figure 5. VdISC1 physically interacts with GhKWL1 independent of the catalytic activity of VdISC1. (A) VdISC1 or VdISC1 $^{3 \mathrm{~A}}$ interaction with GhKWL1 was investigated by BiFC assay. Fusion protein gene GhKWL1:cYFP was transiently co-expressed with VdISC1:nYFP, VdISC1 ${ }^{3 A}: n Y F P$, or $n Y F P$ in tobacco leaves. The yellow fluorescence signals in tobacco pavement cells were observed at $3 \mathrm{~d}$ post-agroinfiltration. The scale bar represents $50 \mu \mathrm{m}$. cYFP, the C-terminal half of YFP; nYFP, the N-terminal half of YFP. (B) VdISC1 coimmunoprecipitated with GhKWL1. Anti-GFP beads were used to purify the protein complex with GFP-fusion proteins. The total proteins (Input) and anti-GFP immunoprecipitate (IP: $\alpha$-GFP) were separated by SDS-PAGE and analyzed by immunoblotting with antibodies to FLAG or GFP. The coexpression of GFP and VdISC1:FLAG was used as a negative control. (C) VdISC1 ${ }^{3 \mathrm{~A}}$ coimmunoprecipitated with GhKWL1. Anti-GFP beads were used to purify the protein complex with GFP-fusion proteins. The total proteins (Input) and anti-GFP immunoprecipitate (IP: $\alpha$-GFP) were separated by SDS-PAGE and analyzed by immunoblotting with antibodies to FLAG or GFP. The coexpression of GFP and VdISC1 ${ }^{3 A}$ :FLAG was used as a negative control. (D) The inducible activity of the GhERF105 promoter in the presence of GhKWL1, VdISC1, or VdISC1 ${ }^{3 A}$. The luciferase activity was determined by the LUC/REN ratio. Error bars indicate the standard deviation of three biological replicates. Asterisks indicate statistical significance as determined by Student's $t$-test $\left({ }^{*} p<0.05,{ }^{* *} p<0.01\right)$. 


\section{Discussion}

Kiwellins are synthesized in many plant species. However, their functions are poorly understood [48]. To investigate the roles of kiwellins, we identified $35 \mathrm{KWL}$ genes in upland cotton. We showed that four GhKWL genes were upregulated by $V$. dahliae infection. Among these four GhKWL proteins, only GhKWL1 was shown to be localized in the nucleus. The nuclear localization of GhKWL1 differed from previous reports in which KWLs of kiwifruit and corn were shown to be apoplastic proteins [38,42,48]. Autoactivation activity and dual-luciferase assays revealed that GhKWL1 participates in the activation of GhERF105, supporting its nuclear localization.

In dicotyledonous species, SA-mediated defense is associated with resistance to biotrophic pathogens, whereas defense responses mediated by jasmonates (JAs) and ethylene (ET) are implicated in resistance to necrotrophic pathogens. With regard to hemibiotrophic pathogens, such as $V$. dahliae, the host plants mainly use SA-mediated resistance pathways as defense against the invasion of the pathogen (during the biotrophic phase) and then adopt JA/ET-mediated defenses to limit the pathogen from spreading (during the necrotrophic phase). Among KWL proteins, only ZmKWL1 and ZmKWL1-b were shown to function in disease resistance [48,49]. The resistance mechanism of ZmKWL1 acts via interaction with Cmu1 to deactivate the pathogenic effector [48]. In the present study, we demonstrated that silencing of GhKWL1 decreased the resistance, whereas overexpression of GhKWL1 enhanced the resistance of plants to V. dahliae. The present data further showed that GhKWL1 could interact with VdISC1, a pathogenic effector produced by V. dahliae. Similar to Cmu1, VdISC1 can weaken plant immunity by reducing the production of SA [11]. However, unlike ZmKWL1 and ZmKWL1-b, which are located in the apoplast, GhKWL1 was localized in the nucleus, suggesting it plays a potential role in regulating gene expression. We further revealed that GhKWL1 could upregulate the expression of ERF genes. Previous studies have shown that ERFs positively regulate PDF1.2 and PR4, which are associated with resistance to Verticillium wilt, in cotton [15,35]. The decreased expression levels of PDF1.2 and PR4 in GhKWL1-silenced and GhERF105-silenced upland cotton plants, and the enhanced expression levels of the two genes in GhKWL1-overexpression Arabidopsis plants, demonstrate that PDF1.2 and PR4 are downstream genes of GhKWL1GhERF105-mediated transcriptional regulation. PDF1.2 and PR4 are typical JA-inducible and ET-inducible genes [51,52]. Accordingly, we suggest that VdISC1 has dual pathogenic functions to subvert the immunity of upland cotton: inhibiting SA biosynthesis by decreasing the accumulation of SA precursors [11] during the biotrophic phase of infection and suppressing the expression of JA/ET-inducible resistance genes by binding with GhKWL1, the up-regulator of $E R F$ genes, during the necrotrophic phase of infection.

Taken together, these results indicate that VdISC1 not only converts isochorismate into DDHB to inhibit SA accumulation [11] but also interacts with GhKWL1, a positive regulator in the resistance of cotton against Verticillium wilt, to suppress the function of GhKWL1 in regulating the expression of genes relevant to the defense response (Figure 6). The upregulation of GhKWL1, in turn, ensures that the biosynthesis of SA proceeds at considerable levels and protects the GhKWL1-GhERFs pathway from inhibition, thus increasing resistance to Verticillium wilt. 


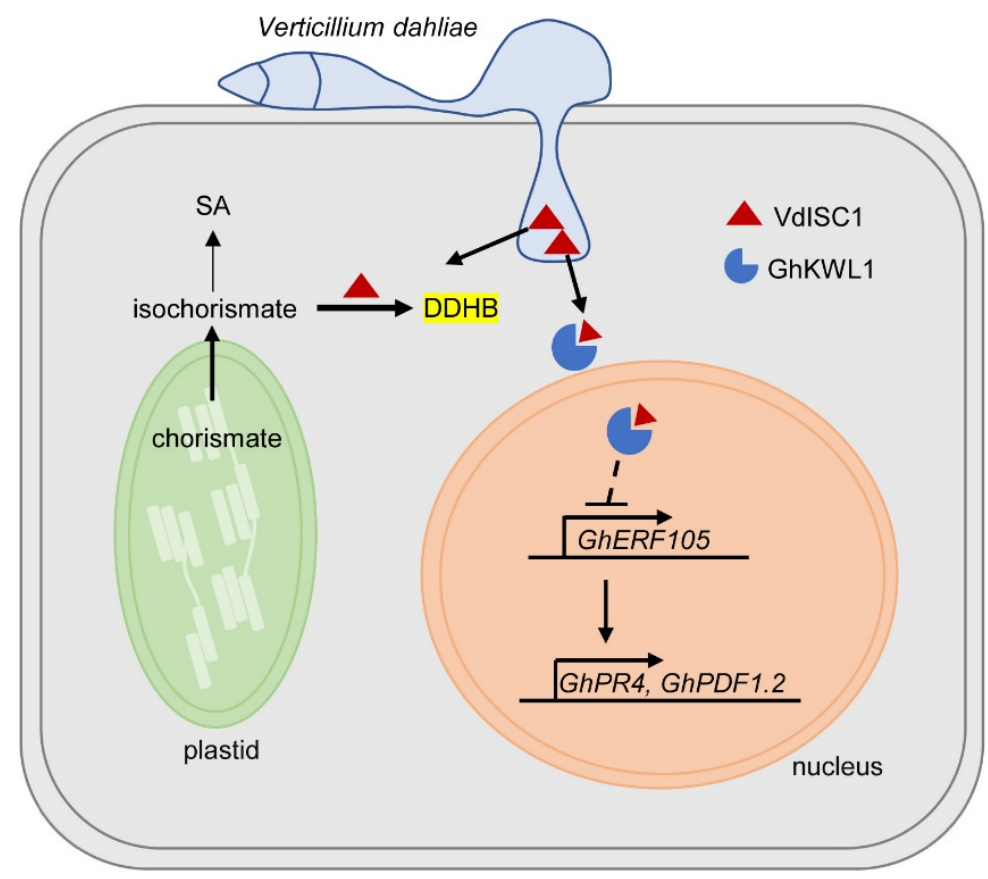

Figure 6. A schematic model of the Verticillium dahliae effector VdISC1 disturbing the plant immune system by two distinct scenarios. (i) VdISC1 (red triangle) interacts with GhKWL1 (blue circle missing a wedge) to inhibit GhKWL1-mediated defense response. (ii) Due to its isochorismate mutase activity, VdISC1 converts isochorismate into 2,3-dihydro-2,3-dihydroxybenzoate (DDHB) to inhibit SA accumulation [11].

\section{Materials and Methods}

\subsection{Vector Construction and Plant Materials}

The coding sequences (without the stop codon) of GhKWL1, GhKWL2, GhKWL3, and GhKWL4 were amplified from root cDNA of upland cotton 'Jimian 14' with the flanking sites BamHI and SalI. GFP was amplified with the flanking sites SalI and EcoRI; then, the GFP fragment was fused at the C-terminal of these GhKWL fragments in the binary vector pLGN [53] by BamHI and EcoRI, respectively. For the pro35S:GhKWL1:YFP construct, the coding sequence (without the stop codon) of GhKWL1 was amplified with the flanking sites KpnI and EcoRI; YFP was amplified with the flanking sites EcoRI and BamHI. The YFP fragment was then fused to the $3^{\prime}$ terminal region of GhKWL1 and inserted into the pLGN vector at the KpnI and BamHI sites. For TRV constructs, the 200 bp sequence, which included the 3'-untranslated region of GhKWL1 and GhERF105, were amplified from upland cotton and separately integrated into the TRV2 plasmid using KpnI and EcoRI to construct VIGS-related vectors. A partial cDNA sequence of GhCLA1, which encodes 1deoxy-D-xylulose-5-phosphate synthase, was cloned into the TRV2 vector as described [15]. The 1830 bp promoter sequence of GhERF105 was amplified from upland cotton 'Jimian $14^{\prime}$ and cloned into the pGreenII 0800-LUC vector [54] between the HindIII and BamHI sites. The coding region of VdlSC1 was amplified from cDNA of $V$. dahliae strain V991 and inserted into the pLGN vector using SalI and EcoRI to construct pro35S:VdlSC1. For the pro35S:VdlSC1 ${ }^{3 A}$ construct, the mutated version of $V d l S C 1^{3 A}$ (D25A, K90A, and C124A) was synthesized with the flanking $K p n I$ and EcoRI restriction sites and inserted into the pLGN vector. For the pro35S:GhKWL1 construct, the coding region of GhKWL1 was inserted into the pLGN vector using BamHI and EcoRI. For the BiFC constructs, the coding region of GhKWL1 (without the stop codon) was fused with $n Y F P$ in the plasmid pEarleyGate201; the coding region of $V d l S C 1$ (without the stop codon) and the mutated version of $V d l S C 1^{3 A}$ were separately fused with $c Y F P$ in the plasmid pEarleyGate202 [55]. The coding sequence of GhKWL1 was cloned into the pLexA vector at the EcoRI and BamHI sites. The sequence for a FLAG tag was added to the $3^{\prime}$ end of VdlSC1 (VdlSC1:FLAG) using PCR amplification 
and ligated into the pLGN vector at the BamHI and EcoRI sites. All constructs except pLexA-GhKWL1 were introduced into A. tumefaciens strain GV3101 for further research. Transformation of $A$. thaliana ecotype Columbia- 0 was performed using the floral dip method [56]. The sequences of all primers are listed in Supplementary Materials, Table S2. The vectors used are listed in Supplementary Materials, Table S3.

\subsection{Sequence Retrieval, Phylogenetic Analysis, Subcellular Localization Prediction and Sequence Alignment}

The maize and kiwifruit genome sequences were obtained from the Kiwifruit Genome Database (http:/ / kiwifruitgenome.org/, accessed on 19 January 2020) and maizeGDB (https://maizegdb.org/, accessed on 20 January 2020), respectively. The genome sequences of Oryza sativa (subsp. japonica) were obtained from the Rice Genome Annotation Project (http:/ / rice.plantbiology.msu.edu/, accessed on 13 April 2021), the tobacco genome sequences were obtained from the National Center for Biotechnology Information databases (https://www.ncbi.nlm.nih.gov/, accessed on 13 April 2021). The BLASTP tool was used to identify KWL homologs using ZmKWL and AcKWL sequences with default parameters in the CottonFGD database (https: / www.cottonfgd.org/, accessed on 25 January 2020) $[50,57]$; the cut-off value was $1.0^{-50}$. The selected cotton KWL proteins were used for further identification of KWLs by searching the cotton database again. All obtained sequences were sorted as unique sequences, and further protein domain searches were performed using InterProScan (http:/ / www.ebi.ac.uk/Tools/pfa/iprscan/, accessed on 26 January 2020). A phylogenetic tree of deduced KWL amino acids was constructed using the neighbor-joining algorithm with default parameters, with 1000 bootstrap replicates as implemented in MEGA6.0 (https: / / www.megasoftware.net/, accessed on 14 April 2021).

The subcellular localization of GhKWLs was predicted using WoLF PSORT (https: / / www.genscript.com/tools/wolf-psort/, accessed on 15 April 2021), PSORT (http:/ / psort1 .hgc.jp/form.html/, accessed on 15 April 2021), and Localizer (http:/ / localizer.csiro.au//, accessed on 15 April 2021).

The KWL protein sequences were aligned using Megalign ${ }^{\mathrm{TM}}$ DNAstar [58] and analyzed with the Gendoc software [59].

\subsection{Transient Expression in Tobacco Epidermal Cells and BiFC Assay}

The overnight culture of Agrobacterium was resuspended and diluted with infiltration buffer ( $10 \mathrm{mM} \mathrm{MgCl}_{2}$ and $100 \mu \mathrm{M}$ acetosyringone) to $\mathrm{OD}_{600}$ of $0.01-0.05$ and then infiltrated into 8-week-old $N$. benthamiana leaves for transient expression. After growth for $3 \mathrm{~d}$ at $25^{\circ} \mathrm{C}$, the infiltrated leaves were harvested for the following analysis.

The BiFC assay was performed as previously described [55]. Agrobacterium tumefaciens infiltration solution containing the pEarleyGate201-pro35S:GhKWL1:cYFP and pEarleyGate202pro35S:VdISC1:n YFP constructs was used to test the interaction between GhKWL1 and VdISC1. Agrobacterium tumefaciens infiltration solution containing the pEarleyGate201pro35S:GhKWL1:cYFP and pEarleyGate202-pro35S:VdISC13A:nYFP constructs was used to test the interaction between GhKWL1 and VdISC1 ${ }^{3 \mathrm{~A}}$. Agrobacterium tumefaciens infiltration solution containing the pEarleyGate201-pro35S:GhKWL1:cYFP and pEarleyGate202pro35S:nYFP constructs were used as a negative control. The interaction was evaluated $3 \mathrm{~d}$ after infiltration.

\subsection{Microscopy Observation}

The fluorescence signal was observed using a Leica SP8 confocal microscope equipped with a HyD detector under a $40 \times$ oil immersion objective lens. The nucleus was stained with DAPI (4',6-diamidino-2-phenylindole), a fluorescent dye that strongly binds to DNA. The acquisition parameters were: GFP, excitation at $488 \mathrm{~nm}$, emission from 496 to $530 \mathrm{~nm}$; YFP, excitation at $514 \mathrm{~nm}$, emission from 526 to $570 \mathrm{~nm}$; RFP, excitation at $552 \mathrm{~nm}$, emission from 558 to $606 \mathrm{~nm}$; and DAPI, excitation at $405 \mathrm{~nm}$, emission from 420 to $464 \mathrm{~nm}$. 


\subsection{Quantitative RT-PCR Analysis}

The total RNA was extracted using the EASYspin Plant RNA Extraction Kit (Aidlab, Beijing, China). After treatment with DNase I (TaKaRa, Kusatsu, Shiga, Japan), $1 \mu \mathrm{g}$ RNA was used to synthesize the first-strand cDNA with the PrimeScript ${ }^{\mathrm{TM}}$ RT Reagent Kit (TaKaRa, Kusatsu, Shiga, Japan). Quantitative PCR was performed on a CFX96 ${ }^{\mathrm{TM}}$ Real-Time System (Bio-Rad, Hercules, CA, USA) using the $1 \times \mathrm{iQ}^{\mathrm{TM}}$ SYBR Green Supermix (Bio-Rad, Hercules, CA, USA) in accordance with the manufacturer's instructions, and the data were analyzed using the native software (Bio-Rad, Hercules, CA, USA). The thermal cycling protocol consisted of a pretreatment $\left(94^{\circ} \mathrm{C}, 3 \mathrm{~min}\right)$ followed by 40 amplification cycles $\left(94{ }^{\circ} \mathrm{C}, 30 \mathrm{~s} ; 56^{\circ} \mathrm{C}, 30 \mathrm{~s}\right.$; and $\left.72{ }^{\circ} \mathrm{C}, 30 \mathrm{~s}\right)$. The data were analyzed using the CFX Maestro software installed on the CFX96 ${ }^{\mathrm{TM}}$ Real-Time System (Bio-Rad, Hercules, CA, USA). Each test was confirmed by three individual runs (biological replicates), and data from one of the replicates was used to generate the expression chart. The ubiquitin gene UBQ7 (GenBank accession no. DQ116441) and actin gene ACTIN2 (AT3G18780.2) served as the reference genes in cotton and Arabidopsis, respectively. Gene-specific primers used for qRT-PCR are listed in Supplementary Materials, Table S2.

\subsection{Virus-Induced Gene Silencing in Cotton and RNA-Seq Analysis}

Agrobacterium tumefaciens infiltration solutions containing the corresponding TRV constructs were prepared according to the previous description [60]. Ten-day-old seedlings of upland cotton were used for infiltration and then grown in a growth chamber under a 16-h-day / 8-h-night photoperiod at $25^{\circ} \mathrm{C}$. After 2 weeks, the silenced plants were used for further analysis, including RNA-seq analysis and inoculation with $V$. dahliae. The albino phenotype of GhCLA1-silenced cotton plants was used as an indicator of VIGS effectivity in each experiment.

Leaves from more than three GhKWL1-silenced plants and the control that was infiltrated with the empty vector were harvested for RNA-seq analysis. The analysis was conducted by Majorbio (http:/ / www.majorbio.com/, accessed on 23 July 2020). The data were analyzed using the Majorbio online analysis system (http:/ /www.majorbio.com/, accessed on 24 July 2020). Genes that showed six-fold downregulation (GhKWL1-silenced plants vs. the control) were screened out and enriched by gene ontology (GO) enrichment analysis.

\subsection{Inoculation Method and Disease Assays}

The defoliating $V$. dahliae isolate V991, originally isolated from an infected upland cotton plant, was used in this study [61]. For the production of a conidial suspension, mycelia were grown on potato dextrose agar medium, then collected and cultured in liquid Czapek's medium. Disease assays with $V$. dahliae were performed as previously described [62]. Upland cotton and Arabidopsis plants in pots were inoculated by drenching the soil with $10 \mathrm{~mL}$ conidial suspension $\left(1 \times 10^{7}\right.$ conidia $\left./ \mathrm{mL}\right)$. Verticillium wilt symptoms were recorded for three inoculated plants, with each gene target harvested at $20 \mathrm{~d}$ postinoculation (dpi) in cotton and $25 \mathrm{~d}$ post-inoculation (dpi) in Arabidopsis. The diseased cotton seedlings were classified into five grades $(0,1,2,3$, and 4$)$ based on the severity of the disease after infection. The disease index was calculated using the formula: Disease index $(\%)=\left(\sum\right.$ (disease grades $\times$ number of infected plants $) /($ total number of plants $\left.\times 4)\right) \times 100$. The quantification of the $V$. dahliae biomass in the plant was conducted in accordance with previous reports $[63,64]$. Stems of three inoculated plants were harvested at $20 \mathrm{dpi}$ for cotton, and leaves of three inoculated plants were harvested at $25 \mathrm{dpi}$ for Arabidopsis. The samples were ground to powder, and genomic DNA was isolated. Analysis by qRT-PCR was conducted using the fungus-specific primer ITS-F in combination with the $V$. dahliaespecific reverse primer ST-VE1-R. Cotton GhUBQ7 (GenBank accession no. DQ116441) and Arabidopsis AtACTIN2 (AT3G18780.2) were used as endogenous plant controls. For the expression analysis of GhKWL genes in upland cotton after inoculation with $V$. dahliae V991, 3-week-old seedlings of G. hirsutum 'Jimian 14' were inoculated by drenching the soil 
with $10 \mathrm{~mL}$ conidial suspension $\left(1 \times 10^{7}\right.$ conidia/mL). The inoculated leaf samples were collected at four time points $(12,24,36$, and $48 \mathrm{~h})$ post-inoculation, with three seedlings collected per sample. Control plants were treated with sterile distilled water $(0 \mathrm{~h})$.

\subsection{Dual-Luciferase Reporter Assay}

The dual-luciferase reporter assay was performed as previously described [54]. The promoter sequence of GhERF105 was cloned into the pGreenII 0800-LUC vector, and the coding region of GhKWL1, VdISC1, and VdISC1 ${ }^{3 A}$ was cloned into the pLGN vector. Dualluciferase reporter activities were measured using the Dual-Glo ${ }^{\circledR}$ Luciferase Assay System (Promega, Madison, Wisconsin, USA).

\subsection{Co-Immunoprecipitation Assay}

For the Co-IP assay, A. tumefaciens infiltration solution containing the pLGNpro35S:GhKWL1:GFP and pLGN-pro35S:VdISC1:FLAG constructs was used to test the interaction between GhKWL1 and VdISC1; the infiltration solution containing the pLGNpro35S:GFP and pLGN-pro35S:VdISC1:FLAG constructs was used as the negative control. Agrobacterium tumefaciens infiltration solution containing the pLGN-pro35S:GhKWL1:GFP and pLGN-pro35S:VdISC1 ${ }^{3 A}: F L A G$ constructs was used to test the interaction between GhKWL1 and VdISC1 ${ }^{3 A}$; the infiltration solution containing the pLGN-pro35S:GFP and pLGN-pro35S:VdISC1 ${ }^{3 A}$ :FLAG constructs was used as the negative control. After $3 \mathrm{~d}$, approximately $1 \mathrm{~g}$ infiltrated leaves of $N$. benthamiana were ground in liquid nitrogen and extracted in $3 \mathrm{~mL}$ extraction buffer $\left(94.7 \mathrm{~mL}\right.$ of $0.2 \mathrm{M} \mathrm{Na}_{2} \mathrm{HPO}_{4}, 5.3 \mathrm{~mL}$ of $0.2 \mathrm{M} \mathrm{NaH}_{2} \mathrm{PO}_{4}$, $1 \mathrm{~g}$ polyvinylpyrrolidone, and $1 \mathrm{~mL} \beta$-mercaptoethanol) supplemented with $0.1 \%$ protease inhibitor cocktail (Thermo Scientific, Rockford, IL, USA, Catalog number 87786). After centrifugation at 20,000 rpm for $10 \mathrm{~min}$, the supernatant was the crude extract of the total protein. For immunoprecipitation, $25 \mu \mathrm{L}$ Anti-GFP mAb-Magnetic beads (MBL, Beijing, China, Catalog number D153-10) was added to $3 \mathrm{~mL}$ of the total protein and incubated at $4{ }^{\circ} \mathrm{C}$ for $1 \mathrm{~h}$ in accordance with the manufacturer's instructions. Proteins immunoprecipitated with the agarose beads were then separated in 10\% SDS-PAGE gel and transferred to a PVDF membrane for western blot analysis. The GFP-fusion protein was detected using a mouse monoclonal antibody against GFP (Thermo Scientific, Rockford, IL, USA, Catalog number MA5-15256) at the dilution 1:1000, and the FLAG-fusion proteins were detected using a mouse monoclonal antibody against FLAG (Thermo Scientific, Rockford, IL, USA, Catalog number MA1-91878) at the dilution 1:1000. A secondary antibody (Thermo Scientific, Rockford, IL, USA, Catalog number 32430), derived from goat and conjugated to horseradish peroxidase, was used for signal detection.

\subsection{Yeast Autoactivation Assay}

The pLexA-GhKWL1 construct was transformed into yeast (Saccharomyces cerevisiae) strain EGY48. Transformed cells were grown on a synthetically defined (SD) medium lacking His and Ura for $4 \mathrm{~d}$. Subsequently, positive transformants were mated overnight and spotted onto QDO (quadruple dropouts SD medium lacking Leu, Trp, Ura and His) plates. 5-Bromo-4-chloro-3-indolyl- $\alpha$-D-galactopyranoside (X- $\alpha$-gal) was used as a substrate for colorimetric detection of $\alpha$-galactosidase activity. Plates were incubated at $30^{\circ} \mathrm{C}$ for $6-12 \mathrm{~d}$. Transformed yeast cells harboring the pLexA or pLexA-53 and pB42AD-T constructs were used as a negative control and positive control, respectively.

Supplementary Materials: The following are available online at https:/ /www.mdpi.com/article/10 $.3390 /$ ijms22147328/s1.

Author Contributions: Investigation, L.W., X.Y. (Xiaohan Yu), J.Z. (Jianyan Zeng), H.R., F.W.; methodology, X.L., D.J., S.S., X.Y. (Xingying Yan), J.Z. (Juan Zhao); Y.P. designed the overall study. All the authors performed the experiments. Y.P., Y.C., and M.Z. wrote the manuscript. All authors have read and agreed to the published version of the manuscript. 
Funding: This research was funded by the National Natural Sciences Foundation of China, grant number 31071463 and 31130039.

Institutional Review Board Statement: Not applicable.

Informed Consent Statement: Not applicable.

Data Availability Statement: The data presented in this study are available on request from the corresponding author. The data are not publicly available due to privacy.

Acknowledgments: We thank Zhiying Ma (Hebei Agricultural University) for kindly providing us with the Gossypium hirsutum L. J14, and we also grateful to Guiliang Jian (Chinese Academy of Agricultural Sciences) for providing the $V$. dahliae strain V991.

Conflicts of Interest: The authors declare no conflict of interest.

\section{References}

1. Jamshed, M.; Jia, F.; Gong, J.; Palanga, K.K.; Shi, Y.; Li, J.; Shang, H.; Liu, A.; Chen, T.; Zhang, Z.; et al. Identification of stable quantitative trait loci (QTLs) for fiber quality traits across multiple environments in Gossypium hirsutum recombinant inbred line population. BMC Genom. 2016, 17, 1-13. [CrossRef]

2. Fradin, E.F.; Thomma, B.P.H.J. Physiology and molecular aspects of Verticillium wilt diseases caused by V. dahliae and V. albo-atrum. Mol. Plant Pathol. 2006, 7, 71-86. [CrossRef] [PubMed]

3. Cai, Y.; Xiaohong, H.; Mo, J.; Sun, Q.; Yang, J.; Liu, J. Molecular research and genetic engineering of resistance to Verticillium wilt in cotton: A review. Afr. J. Biotechnol. 2009, 8, 7363-7372. [CrossRef]

4. $\quad$ Fang, H.; Zhou, H.; Sanogo, S.; Lipka, A.E.; Fang, D.D.; Percy, R.G.; Hughs, S.E.; Jones, D.C.; Gore, M.A.; Zhang, J. Quantitative trait locus analysis of Verticillium wilt resistance in an introgressed recombinant inbred population of Upland cotton. Mol. Breed. 2013, 33, 709-720. [CrossRef]

5. Klosterman, S.J.; Atallah, Z.K.; Vallad, G.E.; Subbarao, K.V. Diversity, pathogenicity, and management of Verticillium Species. Annu. Rev. Phytopathol. 2009, 47, 39-62. [CrossRef]

6. Klimes, A.; Dobinson, K.F.; Thomma, B.P.H.J.; Klosterman, S.J. Genomics spurs rapid advances in our understanding of the biology of vascular wilt pathogens in the genus Verticillium. Annu. Rev. Phytopathol. 2015, 53, 181-198. [CrossRef]

7. Dangl, J.L.; Klosterman, S.J.; Subbarao, K.V.; Kang, S.; Veronese, P.; Gold, S.E.; Thomma, B.P.H.J.; Chen, Z.; Henrissat, B.; Lee, Y.-H.; et al. Comparative genomics yields insights into niche adaptation of plant vascular wilt pathogens. PLoS Pathog. 2011, 7, e1002137. [CrossRef]

8. Jones, J.D.G.; Dangl, J.L. The plant immune system. Nature 2006, 444, 323-329. [CrossRef]

9. Berens, M.L.; Berry, H.M.; Mine, A.; Argueso, C.T.; Tsuda, K. Evolution of hormone signaling networks in plant defense. Annu. Rev. Phytopathol. 2017, 55, 401-425. [CrossRef]

10. Shigenaga, A.M.; Argueso, C.T. No hormone to rule them all: Interactions of plant hormones during the responses of plants to pathogens. Semin. Cell Dev. Biol. 2016, 56, 174-189. [CrossRef]

11. Liu, T.; Song, T.; Zhang, X.; Yuan, H.; Su, L.; Li, W.; Xu, J.; Liu, S.; Chen, L.; Chen, T.; et al. Unconventionally secreted effectors of two filamentous pathogens target plant salicylate biosynthesis. Nat. Commun. 2014, 5, 4686. [CrossRef] [PubMed]

12. Kumar, D. Salicylic acid signaling in disease resistance. Plant Sci. 2014, 228, 127-134. [CrossRef] [PubMed]

13. Li, Y.B.; Han, L.B.; Wang, H.Y.; Zhang, J.; Sun, S.T.; Feng, D.Q.; Yang, C.L.; Sun, Y.D.; Zhong, N.Q.; Xia, G.X. The thioredoxin GbNRX1 Plays a crucial role in homeostasis of apoplastic reactive oxygen species in response to Verticillium dahliae infection in cotton. Plant Physiol. 2016, 170, 2392-2406. [CrossRef]

14. Hu, Q.; Min, L.; Yang, X.; Jin, S.; Zhang, L.; Li, Y.; Ma, Y.; Qi, X.; Li, D.; Liu, H.; et al. Laccase GhLac1 modulates broadspectrum biotic stress tolerance via manipulating phenylpropanoid pathway and jasmonic acid synthesis. Plant Physiol. 2018, 176, 1808-1823. [CrossRef] [PubMed]

15. Yang, C.L.; Liang, S.; Wang, H.Y.; Han, L.B.; Wang, F.X.; Cheng, H.Q.; Wu, X.M.; Qu, Z.L.; Wu, J.H.; Xia, G.X. Cotton major latex protein 28 functions as a positive regulator of the ethylene responsive factor 6 in defense against Verticillium dahliae. Mol. Plant 2015, 8, 399-411. [CrossRef]

16. Gu, Z.; Liu, T.; Ding, B.; Li, F.; Wang, Q.; Qian, S.; Ye, F.; Chen, T.; Yang, Y.; Wang, J.; et al. Two lysin-motif receptor kinases, Gh-LYK1 and Gh-LYK2, contribute to resistance against Verticillium wilt in upland cotton. Front. Plant Sci. 2017, 8, 2133. [CrossRef]

17. Liu, J.; Wang, Y.; Zhao, G.; Zhao, J.; Du, H.; He, X.; Zhang, H. A novel Gossypium barbadense ERF transcription factor, GbERFb, regulation host response and resistance to Verticillium dahliae in tobacco. Physiol. Mol. Biol. Plants 2017, 23, 125-134. [CrossRef]

18. Li, C.; He, X.; Luo, X.; Xu, L.; Liu, L.; Min, L.; Jin, L.; Zhu, L.; Zhang, X. Cotton WRKY1 mediates the plant defense-to-development transition during infection of cotton by Verticillium dahliae by activating JASMONATE ZIM-DOMAIN1 expression. Plant Physiol. 2014, 166, 2179-2194. [CrossRef]

19. He, X.; Zhu, L.; Wassan, G.M.; Wang, Y.; Miao, Y.; Shaban, M.; Hu, H.; Sun, H.; Zhang, X. GhJAZ2 attenuates cotton resistance to biotic stresses via the inhibition of the transcriptional activity of GhbHLH171. Mol. Plant Pathol. 2018, 19, 896-908. [CrossRef] 
20. Cheng, H.Q.; Han, L.B.; Yang, C.L.; Wu, X.M.; Zhong, N.Q.; Wu, J.H.; Wang, F.X.; Wang, H.Y.; Xia, G.X. The cotton MYB108 forms a positive feedback regulation loop with CML11 and participates in the defense response against Verticillium dahliae infection. J. Exp. Bot. 2016, 67, 1935-1950. [CrossRef]

21. Song, R.; Li, J.; Xie, C.; Jian, W.; Yang, X. An overview of the molecular genetics of plant resistance to the Verticillium Wilt pathogen Verticillium dahliae. Int. J. Mol. Sci. 2020, 21, 1120. [CrossRef] [PubMed]

22. Zhang, T.; Zhao, Y.L.; Zhao, J.H.; Wang, S.; Jin, Y.; Chen, Z.Q.; Fang, Y.Y.; Hua, C.L.; Ding, S.W.; Guo, H.S. Cotton plants export microRNAs to inhibit virulence gene expression in a fungal pathogen. Nat. Plants 2016, 2, 16153. [CrossRef]

23. Huang, P.Y.; Catinot, J.; Zimmerli, L. Ethylene response factors in Arabidopsis immunity. J. Exp. Bot. 2016, 67, 1231-1241. [CrossRef]

24. Zhu, X.; Qi, L.; Liu, X.; Cai, S.; Xu, H.; Huang, R.; Li, J.; Wei, X.; Zhang, Z. The wheat ethylene response factor transcription factor PATHOGEN-INDUCED ERF1 mediates host responses to both the necrotrophic pathogen Rhizoctonia cerealis and freezing stresses. Plant Physiol. 2014, 164, 1499-1514. [CrossRef] [PubMed]

25. He, P.; Warren, R.F.; Zhao, T.; Shan, L.; Zhu, L.; Tang, X.; Zhou, J.M. Overexpression of Pti5 in tomato potentiates pathogeninduced defense gene expression and enhances disease resistance to Pseudomonas syringae pv. tomato. Mol. Plant Microbe 2001, 14, 1453-1457. [CrossRef] [PubMed]

26. Abiri, R.; Shaharuddin, N.A.; Maziah, M.; Yusof, Z.N.B.; Atabaki, N.; Sahebi, M.; Valdiani, A.; Kalhori, N.; Azizi, P.; Hanafi, M.M. Role of ethylene and the APETALA2/ethylene response factor superfamily in rice under various abiotic and biotic stress conditions. Environ. Exp. Bot. 2017, 134, 33-44. [CrossRef]

27. Zhao, Y.; Chang, X.; Qi, D.; Dong, L.; Wang, G.; Fan, S.; Jiang, L.; Cheng, Q.; Chen, X.; Han, D.; et al. A novel soybean ERF transcription factor, GmERF113, increases resistance to Phytophthora sojae infection in soybean. Front. Plant Sci. 2017, 8, 299. [CrossRef] [PubMed]

28. Jin, J.H.; Zhang, H.X.; Ali, M.; Wei, A.M.; Luo, D.X.; Gong, Z.H. The CaAP2/ERF064 regulates dual functions in pepper: Plant cell death and resistance to Phytophthora capsici. Int. J. Mol. Sci. 2019, 10, 541. [CrossRef]

29. Brown, R.L.; Kazan, K.; McGrath, K.C.; Maclean, D.J.; Manners, J.M. A role for the GCC-box in jasmonate-mediated activation of the PDF1.2 gene of Arabidopsis. Plant Physiol. 2003, 132, 1020-1032. [CrossRef]

30. Meng, X.; Xu, J.; He, Y.; Yang, K.Y.; Mordorski, B.; Liu, Y.; Zhang, S. Phosphorylation of an ERF transcription factor by Arabidopsis MPK3/MPK6 regulates plant defense gene induction and fungal resistance. Plant Cell 2013, 25, 1126-1142. [CrossRef]

31. Moffat, C.S.; Ingle, R.A.; Wathugala, D.L.; Saunders, N.J.; Knight, H.; Knight, M.R. ERF5 and ERF6 Play Redundant Roles as positive regulators of JA/Et-mediated defense against Botrytis cinerea in Arabidopsis. PLoS ONE 2012, 7, e35995. [CrossRef] [PubMed]

32. Onate-Sanchez, L.; Anderson, J.P.; Young, J.; Singh, K.B. AtERF14, a member of the ERF family of transcription factors, plays a nonredundant role in plant defense. Plant Physiol. 2007, 143, 400-409. [CrossRef] [PubMed]

33. Pre, M.; Atallah, M.; Champion, A.; De Vos, M.; Pieterse, C.M.; Memelink, J. The AP2/ERF domain transcription factor ORA59 integrates jasmonic acid and ethylene signals in plant defense. Plant Physiol. 2008, 147, 1347-1357. [CrossRef]

34. Zarei, A.; Korbes, A.P.; Younessi, P.; Montiel, G.; Champion, A.; Memelink, J. Two GCC boxes and AP2/ERF-domain transcription factor ORA59 in jasmonate/ethylene-mediated activation of the PDF1.2 promoter in Arabidopsis. Plant Mol. Biol. 2011, 75, 321-331. [CrossRef]

35. Guo, W.; Jin, L.; Miao, Y.; He, X.; Hu, Q.; Guo, K.; Zhu, L.; Zhang, X. An ethylene response-related factor, GbERF1-like, from Gossypium barbadense improves resistance to Verticillium dahliae via activating lignin synthesis. Plant Mol. Biol. 2016, 91, 305-318. [CrossRef]

36. Meng, X.; Li, F.; Liu, C.; Zhang, C.; Wu, Z.; Chen, Y. Isolation and characterization of an ERF transcription factor gene from cotton (Gossypium barbadense L.). Plant Mol. Biol. Rep. 2009, 28, 176-183. [CrossRef]

37. Liu, Y.; Liu, X.; Long, L.; Wang, W.; Sun, Q.; Li, B.; Wang, C.; Cheng, J.; Zhang, Y.; Xie, Y.; et al. GbABR1 is associated with Verticillium wilt resistance in cotton. Biologia 2018, 73, 449-457. [CrossRef]

38. Tamburrini, M.; Cerasuolo, I.; Carratore, V.; Stanziola, A.A.; Zofra, S.; Romano, L.; Camardella, L.; Ciardiello, M.A. Kiwellin, a novel protein from kiwi fruit. Purification, biochemical characterization and identification as an allergen. Protein J. 2005, 24, 423-429. [CrossRef]

39. Tuppo, L.; Giangrieco, I.; Palazzo, P.; Bernardi, M.L.; Scala, E.; Carratore, V.; Tamburrini, M.; Mari, A.; Ciardiello, M.A. Kiwellin, a modular protein from green and gold kiwi fruits evidence of in vivo and in vitro processing and IgE binding. J. Agr. Food Chem. 2008, 56, 3812-3817. [CrossRef]

40. Maddumage, R.; Nieuwenhuizen, N.J.; Bulley, S.M.; Cooney, J.M.; Green, S.A.; Atkinson, R.G. Diversity and relative levels of actinidin, kiwellin, and thaumatin-like allergens in 15 varieties of kiwifruit (Actinidia). J. Agr. Food Chem. 2013, 61, 728-739. [CrossRef] [PubMed]

41. Bernardi, M.L.; Picone, D.; Tuppo, L.; Giangrieco, I.; Petrella, G.; Palazzo, P.; Ferrara, R.; Tamburrini, M.; Mari, A.; Ciardiello, M.A. Physico-chemical features of the environment affect the protein conformation and the immunoglobulin E reactivity of kiwellin (Act d 5). Clin. Exp. Allergy 2010, 40, 1819-1826. [CrossRef]

42. Antonietta Ciardiello, M.; Giangreco, I.; Tuppo, L.; Tamburrini, M.; Buccheri, M.; Palazzo, P.; Bernardi, M.L.; Ferrara, R.; Mari, A. Influence of the natural ripening stage, cold storage, and ethylene treatment on the protein and IgE-binding profiles of green and gold kiwi fruit extracts. J. Agr. Food Chem. 2009, 57, 1565. [CrossRef] 
43. Bublin, M.; Pfister, M.; Radauer, C.; Oberhuber, C.; Bulley, S.; Dewitt, A.M.; Lidholm, J.; Reese, G.; Vieths, S.; Breiteneder, H.; et al. Component-resolved diagnosis of kiwifruit allergy with purified natural and recombinant kiwifruit allergens. J. Allergy Clin. Immunol. 2010, 125, 687-694. [CrossRef]

44. Yin, T.; Mosquera, T.; Alvarez, M.F.; Jiménez-Gómez, J.M.; Muktar, M.S.; Paulo, M.J.; Steinemann, S.; Li, J.; Draffehn, A.; Hofmann, A.; et al. Targeted and untargeted approaches unravel novel candidate genes and diagnostic SNPs for quantitative resistance of the potato (Solanum tuberosum L.) to Phytophthora infestans causing the late blight disease. PLoS ONE 2016, 11, e0156254. [CrossRef]

45. Quintana-Camargo, M.; Méndez-Morán, L.; Ramirez-Romero, R.; Gurrola-Díaz, C.M.; Carapia-Ruiz, V.; Ibarra-Laclette, E.; Délano-Frier, J.P.; Sánchez-Hernández, C. Identification of genes differentially expressed in husk tomato (Physalis philadelphica) in response to whitefly (Trialeurodes vaporariorum) infestation. Acta Physiol. Plant 2015, 37, 29. [CrossRef]

46. Ashfaq Ali, E.A.; Sandin, M.; Resjö, S.; Lenman, M.; Hedley, P.; Levander, F.; Andreasson, E. Quantitative proteomics and transcriptomics of potato in response to Phytophthora infestansin compatible and incompatible interactions. BMC Genom. 2014, 15, 497. [CrossRef]

47. Lanver, D.; Müller, A.N.; Happel, P.; Schweizer, G.; Haas, F.B.; Franitza, M.; Pellegrin, C.; Reissmann, S.; Altmüller, J.; Rensing, S.A.; et al. The biotrophic development of Ustilago maydis studied by RNA-seq analysis. Plant Cell 2018, 30, 300-323. [CrossRef] [PubMed]

48. Han, X.; Altegoer, F.; Steinchen, W.; Binnebesel, L.; Schuhmacher, J.; Glatter, T.; Giammarinaro, P.I.; Djamei, A.; Rensing, S.A.; Reissmann, S.; et al. A kiwellin disarms the metabolic activity of a secreted fungal virulence factor. Nature 2019, 565, 650-653. [CrossRef] [PubMed]

49. Altegoer, F.; Weiland, P.; Giammarinaro, P.I.; Freibert, S.-A.; Binnebesel, L.; Han, X.; Lepak, A.; Kahmann, R.; Lechner, M.; Bange, G. The two paralogous kiwellin proteins KWL1 and KWL1-b from maize are structurally related and have overlapping functions in plant defense. J. Biol. Chem. 2020, 295, 7816-7825. [CrossRef]

50. Liu, X.; Zhao, B.; Zheng, H.J.; Hu, Y.; Lu, G.; Yang, C.Q.; Chen, J.D.; Chen, J.J.; Chen, D.Y.; Zhang, L.; et al. Gossypium barbadense genome sequence provides insight into the evolution of extra-long staple fiber and specialized metabolites. Sci. Rep. 2015, 5, 14139. [CrossRef]

51. Manners, J.M.; Penninckx, I.A.; Vermaere, K.; Kazan, K.; Brown, R.L.; Morgan, A.; Maclean, D.J.; Curtis, M.D.; Cammue, B.P.; Broekaert, W.F. The promoter of the plant defensin gene PDF1.2 from Arabidopsis is systemica. Plant Mol. Biol. 1998, 38, 1071-1080. [CrossRef]

52. Shin, R. Ectopic expression of Tsi1 in transgenic hot pepper plants enhances host resistance to viral, bacterial, and oomycete pathogens. Mol. Plant-Microbe Interact. 2002, 15, 983-989. [CrossRef]

53. Zeng, J.; Zhang, M.; Hou, L.; Bai, W.; Yan, X.; Hou, N.; Wang, H.; Huang, J.; Zhao, J.; Pei, Y. Cytokinin inhibits cotton fiber initiation by disrupting PIN3a-mediated asymmetric accumulation of auxin in the ovule epidermis. J. Exp. Bot. 2019, 70, 3139-3151. [CrossRef]

54. Hellens, R.P.; Allan, A.C.; Friel, E.N.; Bolitho, K.; Grafton, K.; Templeton, M.D.; Karunairetnam, S.; Gleave, A.P.; Laing, W.A. Transient expression vectors for functional genomics, quantification of promoter activity and RNA silencing in plants. Plant Methods 2005, 1, 13. [CrossRef]

55. Duan, X.; Zhang, Z.; Wang, J.; Zuo, K. Characterization of a novel cotton subtilase gene GbSBT1 in response to extracellular stimulations and its role in Verticillium resistance. PLoS ONE 2016, 11, e0153988. [CrossRef]

56. Clough, S.J.; Bent, A.F. Floral dip a simplified method for Agrobacterium-mediated transformation of Arabidopsis thaliana. Plant J. 1998, 16, 735-743. [CrossRef] [PubMed]

57. Zhu, T.; Liang, C.; Meng, Z.; Sun, G.; Meng, Z.; Guo, S.; Zhang, R. CottonFGD: An integrated functional genomics database for cotton. BMC Plant Biol. 2017, 17, 101. [CrossRef] [PubMed]

58. Burland, T.G. DNASTAR's Lasergene sequence analysis software. In Bioinformatics Methods and Protocols; Humana Press: Totowa, NJ, USA, 2000.

59. Nicholas, K.B.; Nicholas, B.H., Jr.; Deerfield, D.W., III. GeneDoc: Analysis and visualization of genetic variation. Embent News 1996, 4, 14. [CrossRef]

60. Fradin, E.F.; Zhang, Z.; Juarez Ayala, J.C.; Castroverde, C.D.; Nazar, R.N.; Robb, J.; Liu, C.M.; Thomma, B.P. Genetic dissection of Verticillium wilt resistance mediated by tomato Ve1. Plant Physiol. 2009, 150, 320-332. [CrossRef] [PubMed]

61. Chen, J.Y.; Liu, C.; Gui, Y.J.; Si, K.W.; Zhang, D.D.; Wang, J.; Short, D.P.G.; Huang, J.Q.; Li, N.Y.; Liang, Y.; et al. Comparative genomics reveals cotton-specific virulence factors in flexible genomic regions in Verticillium dahliae and evidence of horizontal gene transfer from Fusarium. New Phytol. 2018, 217, 756-770. [CrossRef]

62. Han, L.B.; Li, Y.B.; Wang, F.X.; Wang, W.Y.; Liu, J.; Wu, J.H.; Zhong, N.Q.; Wu, S.J.; Jiao, G.L.; Wang, H.Y.; et al. The cotton apoplastic protein CRR1 stabilizes chitinase 28 to facilitate defense against the fungal pathogen Verticillium dahliae. Plant Cell 2019, 31, 520-536. [CrossRef] [PubMed]

63. Ellendorff, U.; Fradin, E.F.; de Jonge, R.; Thomma, B.P. RNA silencing is required for Arabidopsis defence against Verticillium wilt disease. J. Exp. Bot. 2009, 60, 591-602. [CrossRef] [PubMed]

64. Song, Y.; Liu, L.; Wang, Y.; Valkenburg, D.J.; Zhang, X.; Zhu, L.; Thomma, B. Transfer of tomato immune receptor Ve1 confers Ave1-dependent Verticillium resistance in tobacco and cotton. Plant Biotechnol. J. 2018, 16, 638-648. [CrossRef] [PubMed] 